\title{
On the Concept of Circle and Angle in Galilean Plane
}

\author{
Abdullah Kurudirek, Hüseyin Akça \\ Eğitim Fakültesi Matematik Bölümü, Işık Üniversitesi, Erbil, Irak \\ Email: drcebir@hotmail.com, huseyinakcha@gmail.com \\ Received 24 January 2015; accepted 8 February 2015; published 12 February 2015 \\ Copyright (C) 2015 by authors and OALib. \\ This work is licensed under the Creative Commons Attribution International License (CC BY). \\ http://creativecommons.org/licenses/by/4.0/ \\ (c) (i) Open Access
}

\begin{abstract}
In this paper, we try to show what some basic definitions like angle and circle which are taught in Euclidean plane at secondary and high schools, mean in Galilean plane. Furthermore we try and target to introduce the results of angle and circle concepts, comparing different situations of the same definitions in Galilean and Euclidean planes.
\end{abstract}

\section{Keywords}

Galilean Plane, Special Lines, Negative Angle, Parabolic Measure, Circle, Cycle

Subject Areas: Geometry, Mathematical Analysis

\section{Giriş}

Bilindiği gibi, Galileo düzleminde alınan herhangi $A\left(x_{1}, y_{1}\right)$ ve $B\left(x_{2}, y_{2}\right)$ noktaları arasındaki mesafe $d_{1}=\left|x_{2}-x_{1}\right|$ eşitliği ile tanımlanıyordu. $x_{2}-x_{1}=0$ olduğu durumda ise, mesafe $d_{2}=\left|y_{2}-y_{1}\right|$ eşitliği ile tanımlanmaktaydı [1]. Eğer noktalar oy-koordinat eksenine parallel doğrular üzerinde olursa aralarındaki mesafe ikinci eşitlik ile hesaplanır. Bundandolayı, oy-koordinat eksenine paralel doğrulara özel doğrular adı verilir [2].

\section{Bulgular}

Şimdi, iki nokta arasındaki mesafe kavramından ve çemberin Öklid düzlemindeki tanımından faydalanarak Galileo düzleminde çemberi tanımlayabiliriz.

Tanım: Galileo düzleminde, verilen herhangi bir noktaya eşit mesafede bulunan noktaların geometrik yerine çember denir. Eğer $O\left(x_{0}, y_{0}\right)$ çemberin merkezi, $r$ çemberin yarıçapı ve $M(x, y)$ çember üzerinde herhangi bir nokta olsa bu çemberin denklemi, 


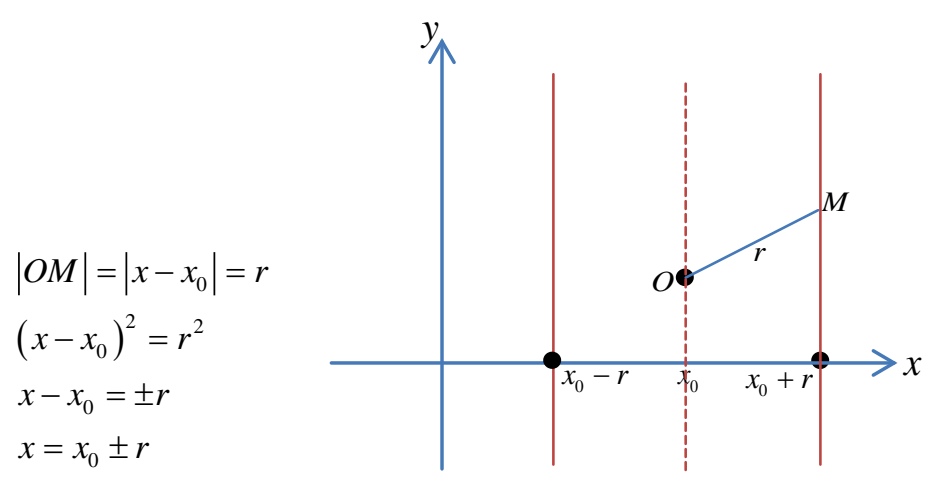

eşitliği ile ifade edilir.

Çemberin merkezi orijinde $(O(0,0))$ olursa o zaman çemberin denklemi $x^{2}=r^{2}$ olur ve burada çemberin merkezi de özel doğru noktalarından oluşur. O halde, Galileo düzlemindeki çemberin iki özel doğrudan oluştuğunu söyleyebiliriz [3].

Galileo düzlemindeki açı kavramı da yine Öklid düzleminde kikavramlardan yararlanılarak tanımlanır. Açının ölçüsü olarak; merkezi, açı ucunda olan çember yayının uzunluğu alınır [4].

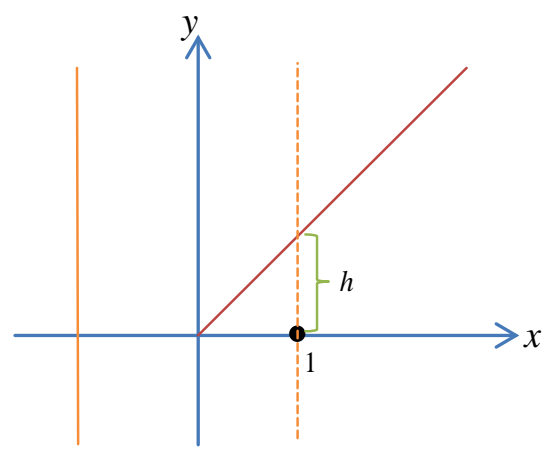

Eğer $y=k_{1} x$ ve $y=k_{2} x$ doğruları, köşesiorijinde bulunan açının kenarları olursa bu açının ölçüsü $h=\left|k_{2}-k_{1}\right|$ ile hesaplanır.

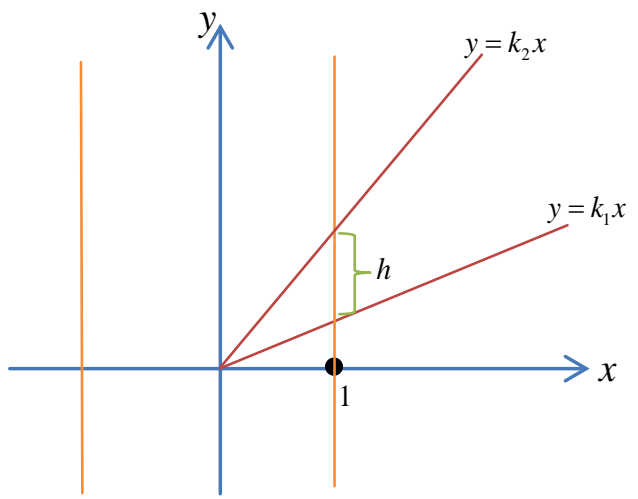

Galileo düzlemindeki açı $0 \leq h \leq \infty$ arasında olup, buna açının parabolik ölçümü denir. Galileo düzlemindeki açı kavramını verme ve onun Öklid anlamındaki açı kavramı ile karşılaştırılmasını yapma fikri, okullarda normal geometri ders saatlerinin haricinde ki zamanlarda verilebilecek konulardır. Açı kavramınınher iki durumda verilebileceğinin mümkün olduğunu gösterdiği gibi aynı zamanda açı ölçüsünün sınırlandırılamayışı hakkında da malumat vermektedir.

ox-yatay ve oy-dikey koordinat eksenleri boyunca alınan dar açının parabolik anlamda ölçümü ve onların büyüklüklerinin kıyaslaması pratikde oldukça kolaydır.Burada açıyı, açıölçer yardımıyla ölçerken, açı ölçerin 
sade ve iyi tanımlanmasından dolayı hesaplamanın çok kolay olduğu görülür.

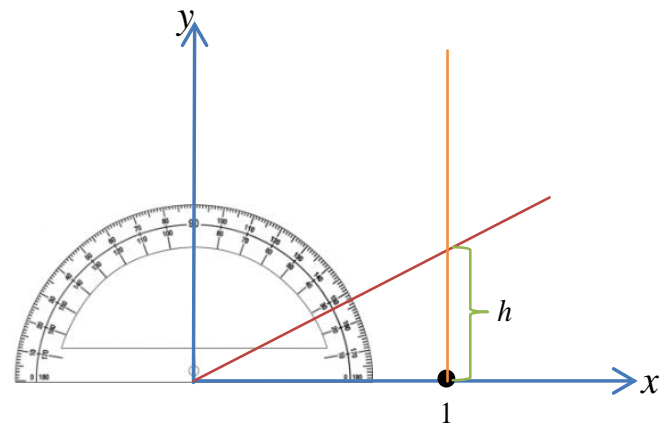

Galileo düzleminde açı kavramının kendisine aitgeniş özellikleri vardır. Mesela özel doğru, açının kenarları arasında olduğunda Galileo düzlemi, çemberi onun iki kenarını kesememektedir. Bu durumda açı kenarlarından birinindevam ettirilerek çember yayı ile kesişmesinden faydalanılır.

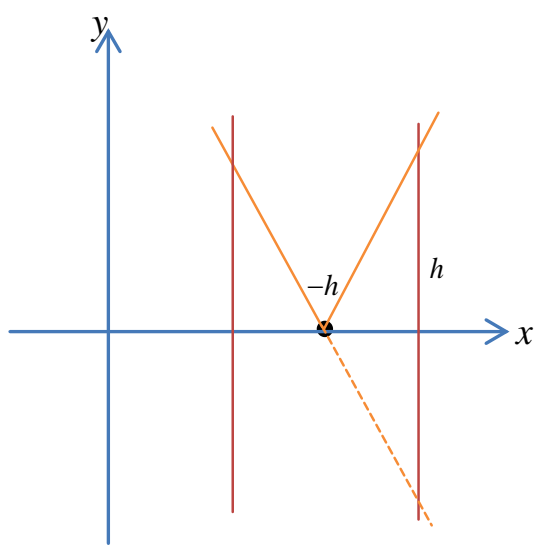

Burada elde edilen dış açı, verilen açı ölçüsü şeklinde alınır ve bazı durumlarda bu negatif açı olarak da hesaplanır. Ayrıca, doğal olarak Galileo düzleminde dar açı, dik açı ve geniş açı düşüncelerinden bahsedemeyiz.

Galileo düzleminde açı kavramı aşağıdaki özelliklere sahiptir.

1) Dikaçılar birbirlerine denktir.

2) Komşu açılar denk ve zıt işaretlidir, yani komşu açıların toplamı sıfırdır, $h+(-h)=0$.

3) Ortak kenara sahip iki açının toplamı aşağıdaki gibi ifade edilir.

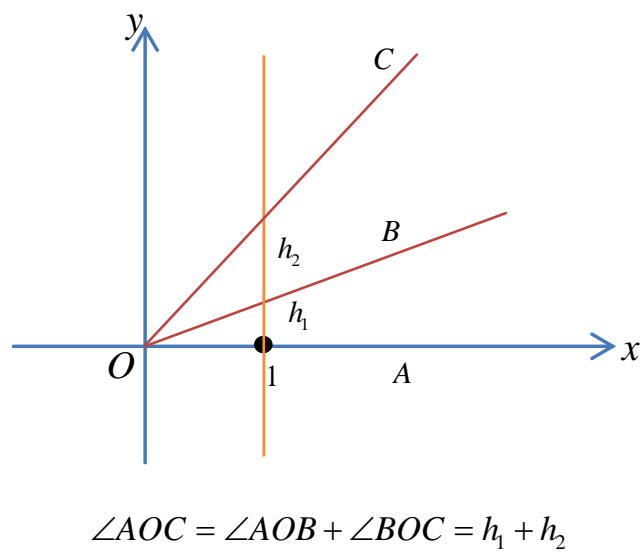

4) Kenarları paralel olan açıların ölçümleri mutlak değerlerine denktir.

Öklid düzlemindeki paralel iki doğruyu kesen başka bir doğruyla meydana gelen açıların kendi arasındaki 
denkliklerini yada mutlak değerce denkliğinin ispatını göstermek öğrenciler için ilginç bir ödev konusu olabilir. Bilindiği gibi, Öklid geometrisindeki çember; "Verilen herhangi bir $A B$ doğru parçası, her bir noktasından aynı açı altında görünen noktaların geometrik yeri” şeklinde de ele alınarak tanımlanabilir.

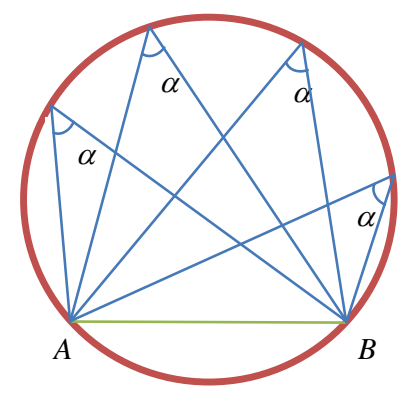

Şimdi, Galileo düzleminde bu özelliğe sahip olan noktaların geometrik yerine bakalım.

Teorem: Galileo düzleminde verilen $A B$ doğru parçasının her bir noktasından aynı açı altında görülen noktaların geometrik yeri bir paraboldür. Burada parabolün simetri ekseni özel doğrudur.

İspat: $A\left(x_{1}, y_{1}\right)$ ve $B\left(x_{2}, y_{2}\right)$ verilen $A B$ doğru parçasının uç noktaları olsun. $C\left(x_{0}, y_{0}\right)$ noktasından $A B$ doğru parçasına $h$ açısıylaşekildeki gibi $C A$ ve $C B$ doğruları arasındaki açı aynı $h$ açısına denktir. Bunu göstermek için $C A$ ve $C B$ doğrularının denklemlerini bulup onlar arasındaki açıyı $h$ 'yeeşitleyelim.

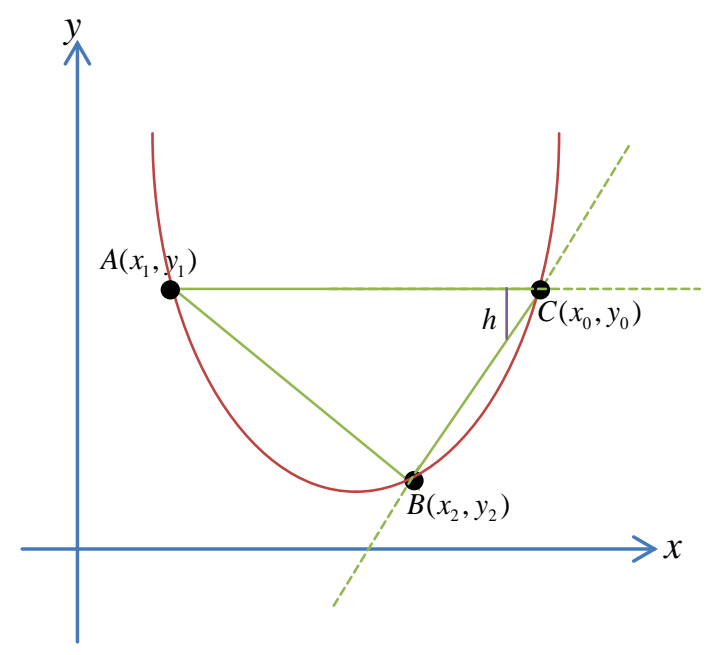

Verilen iki noktadan geçen doğru denklem formülünü kullanarak;

$$
A C: y-y_{0}=\frac{y_{0}-y_{1}}{x_{0}-x_{1}}\left(x-x_{0}\right) \text { ve } B C: y-y_{0}=\frac{y_{0}-y_{2}}{x_{0}-x_{2}}\left(x-x_{0}\right)
$$

denklemlerini yazabiliriz. Ayrıca bu doğruların eğimlerini sırasıyla

$$
k_{1}=\frac{y_{0}-y_{1}}{x_{0}-x_{1}} \text { ve } k_{2}=\frac{y_{0}-y_{2}}{x_{0}-x_{2}}
$$

ile gösterecek olursak, $\quad x_{2}-x_{1} \neq 0$ olduğunu da göz önünde bulundurarak;

$$
\begin{aligned}
& h=\left|k_{2}-k_{1}\right|=\left|\frac{y_{0}-y_{2}}{x_{0}-x_{2}}-\frac{y_{0}-y_{1}}{x_{0}-x_{1}}\right|, \\
& h=\frac{\left(y_{0}-y_{2}\right)\left(x_{0}-x_{1}\right)-\left(y_{0}-y_{1}\right)\left(x_{0}-x_{2}\right)}{\left(x_{0}-x_{1}\right)\left(x_{0}-x_{2}\right)}
\end{aligned}
$$


elde edilir.

Gerekli cebirsel işlemler yapıldığında,

$$
\begin{aligned}
& h\left(x_{0}-x_{1}\right)\left(x_{0}-x_{2}\right)=\left(y_{0}-y_{2}\right)\left(x_{0}-x_{1}\right)-\left(y_{0}-y_{1}\right)\left(x_{0}-x_{2}\right), \\
& \Rightarrow h x_{0}^{2}-h x_{0} x_{1}-h x_{0} x_{2}+h x_{1} x_{2}=y_{0}\left(x_{2}-x_{1}\right)-y_{2} x_{0}+y_{2} x_{1}+y_{1} x_{0}-y_{1} x_{2}, \\
& \Rightarrow y_{0}=\frac{h x_{0}^{2}-h x_{0} x_{1}-h x_{0} x_{2}+h x_{1} x_{2}+y_{2} x_{0}-y_{2} x_{1}-y_{1} x_{0}+y_{1} x_{2}}{x_{2}-x_{1}}, \\
& \Rightarrow y_{0}=\frac{h}{x_{2}-x_{1}} x_{0}^{2}+\frac{y_{2}-y_{1}-h x_{2}-h x_{1}}{x_{2}-x_{1}} x_{0}+\frac{y_{1} x_{2}-y_{2} x_{1}+h x_{2} x_{1}}{x_{2}-x_{1}}
\end{aligned}
$$

bulunur.

Buradan da katsayıları,

$$
A=\frac{h}{x_{2}-x_{1}}, B=\frac{y_{2}-y_{1}-h x_{2}-h x_{1}}{x_{2}-x_{1}}, C=\frac{y_{1} x_{2}-y_{2} x_{1}+h x_{2} x_{1}}{x_{2}-x_{1}}
$$

şeklinde seçersek

$$
y_{0}=A x_{0}^{2}+B x_{0}+C
$$

deklemi elde edilir ki buda bir paraboldür.

Gerçekten de bu denklem $\left(x_{0}, y_{0}\right)$ noktaları, simetri ekseni özel doğruda olan parabole ait olduğunu ve $x_{2}-x_{1} \neq 0$ olduğunda doğru parçasının $o x$-koordinat eksenine paralel olmadığını gösterir. Yani, bu incelenen doğru parçası özel doğru üzerinde değildir. Çemberin bu tanımını veren noktaların geometrik yerine cycle denir [4]. Buradan, Galileo düzleminde Öklid düzleminin çemberine aitözelliklerin olduğu doğrunun, parabol (cycle) olduğu sonucu çıkar.

Yine bilindiği gibi, Galileo düzlemindeki hareket $\left\{\begin{array}{l}x^{\prime}=x+a \\ y^{\prime}=h x+y+b\end{array}\right.$ denklemi ile ve koordinat eksenlerini $h$ açısına döndürme ise $\left\{\begin{array}{l}x^{\prime}=x \\ y^{\prime}=h x+y\end{array}\right.$ ile tanımlanır [2].

\section{Sonuç ve Tartışma}

Öklid düzleminde merkezi orjinde bulunan çember, koordinat düzlemini döndürüldükçe çember üzerindeki noktalar çember boyunca yerleşir, ama şekil değiştirmez. Galileo düzlemindeki cycle'ında bu özelliğe sahip olduğu gösterilebilir. Bu durumöğrenciler için düzlemi kendi içinde bir birimlik döndürüş özelliklerini öğrenmek için ödev olarak bırakılabilinir.

\section{References}

[1] Artıkbayev, A., Kurudirek, A. and Akça, H. (2013) Occurrence of Galilean Geometry. Applied and Computational Mathematics, 2, 115-117.

[2] Артыкбаев, А. and Соколов, Д.Д. (1991) Геометрия в целом в плоском пространстве-времени. Ташкент. Изд. «Фан».

[3] Kurudirek, A., Akça, H. and Erdoğan, M. (2013) On Geometries in Affine Plane. Applied and Computational Mathematics, 2, 127-129. http://dx.doi.org/10.11648/j.acm.20130206.13

[4] Yaglom, I.M. (1979) A Simple Non-Euclidean Geometry and Its Physical Basis. Springer-Verlag, New York. 
Scientific Research Publishing (SCIRP) is one of the largest Open Access journal publishers. It is currently publishing more than 200 open access, online, peer-reviewed journals covering a wide range of academic disciplines. SCIRP serves the worldwide academic communities and contributes to the progress and application of science with its publication.

Other selected journals from SCIRP are listed as below. Submit your manuscript to us via either submit@scirp.org or Online Submission Portal.
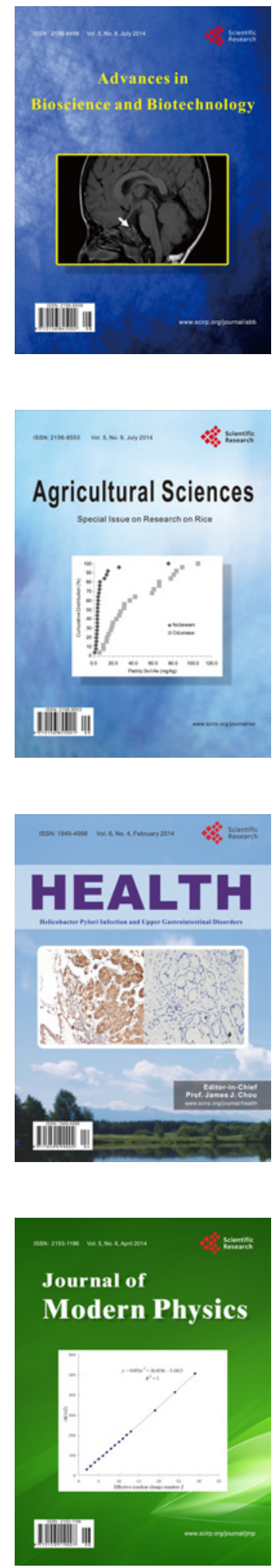
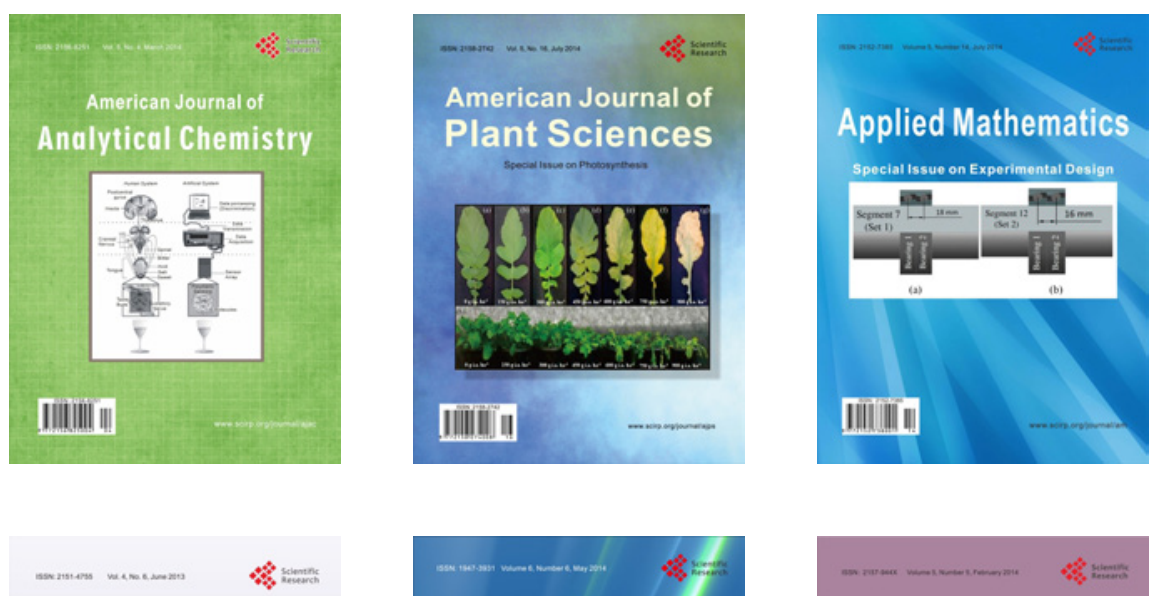

Creative Education
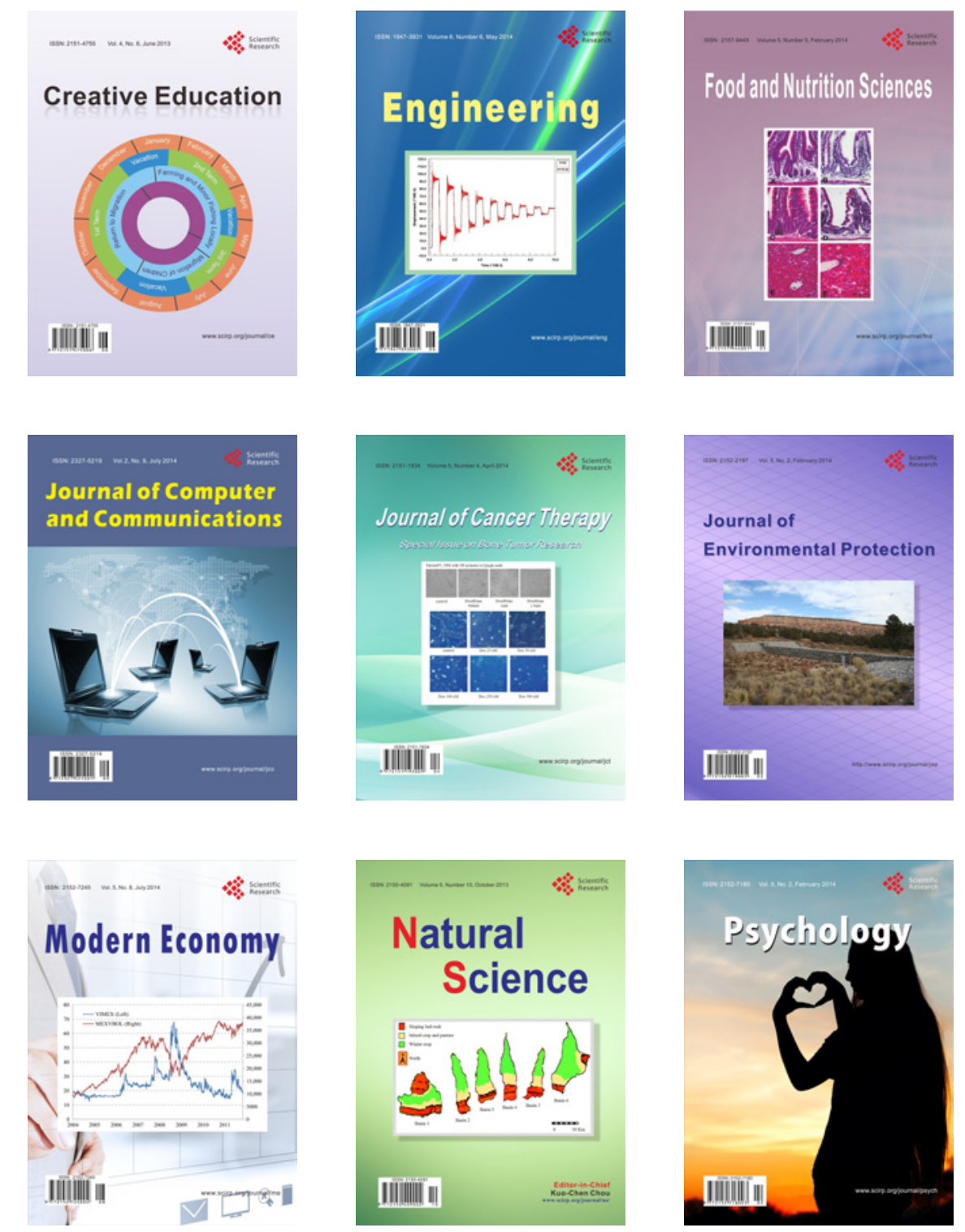